\title{
Achievement of Prolonged Oxygen Detection in Room Temperature Ionic Liquids on Mechanically Polished Platinum Screen-Printed Electrodes
}

\author{
Junqiao Lee, Damien W. M. Arrigan and Debbie S. Silvester ${ }^{*}$
}

Nanochemistry Research Institute, Department of Chemistry, Curtin University, GPOBox U1987, Perth, Western Australia 6845

*Author to whom all correspondence should be addressed

E.mail: d.silvester-dean@curtin.edu.au

Tel: +61 (0) 892667148

FAX: +61 (0) 892662300 


\section{Abstract}

The demonstration of prolonged amperometric detection of oxygen in room temperature ionic liquids (RTILs) was achieved by the use of mechanical polishing to activate platinum screen-printed electrodes (Pt-SPEs). The RTILs studied were 1-ethyl-3-methylimidazolium bis(trifluoromethylsulfonyl)imide $\left(\left[\mathrm{C}_{2} \mathrm{mim}\right]\left[\mathrm{NTf}_{2}\right]\right) \quad$ and $\quad N$-butyl- $N$-methyl-pyrrolidinium $\quad$ bis(trifluoromethylsulfonyl)imide ([C $\mathrm{C}_{4}$ mpyrr $\left.]\left[\mathrm{NTf}_{2}\right]\right)$. It was found that voltammetry on polished Pt-SPEs exhibited less deterioration (in terms of voltammogram shapes, stability of peak currents, and appearance of contaminant peaks) from long-term consecutive cyclic voltammetry cycling under $100 \%$ vol. oxygen flow in both RTILs. The detection capability of these RTIL/Pt-SPE systems, initially subjected to long-term consecutive voltammetric cycling, was also investigated by cyclic voltammetry (CV) and long-term chronoamperometry (LTCA). Current vs. concentration plots were linear on both unpolished and polished electrodes for 10-100 \% vol. $\mathrm{O}_{2}$ (using CV) and 0.1-5 \% vol. $\mathrm{O}_{2}$ (using LTCA). However, sensitivities and limits of detection (LODs) from CV were found to improve significantly on polished electrodes compared to unpolished electrodes, particularly in $\left[\mathrm{C}_{2} \operatorname{mim}\right]\left[\mathrm{NTf}_{2}\right]$, but also moderately in [C $\mathrm{C}_{4}$ mpyrr][ $\left.\mathrm{NTf}_{2}\right]$. The lowest LODs (of ca. $0.1 \%$ vol. $\mathrm{O}_{2}$ ) were found on polished SPEs using LTCA, with the most stable responses observed in $\left[\mathrm{C}_{4} \mathrm{mpyrr}\right]\left[\mathrm{NTf}_{2}\right]$. Calibration graphs could not be obtained on unpolished electrodes in both RTILs using LTCA. The results show that polishing markedly improves the analytical performances of Pt-SPEs for oxygen sensing in RTILs. The reusability of such disposable Pt-SPEs, after the surfaces had been experimentally fouled, was also demonstrated through the use of polishing. Mechanical polishing of Pt-SPE devices offers a viable approach to performance improvement for amperometric gas sensing.

Keywords: Oxygen reduction, screen printed electrodes, polishing, room temperature ionic liquids, cyclic voltammetry, chronoamperometry 


\section{Introduction}

The oxygen $\left(\mathrm{O}_{2}\right)$ reduction reaction $(\mathrm{ORR})$ is vital for biological aerobic respiration and metabolism, and in fuel cells. ${ }^{1}$ The sensing of $\mathrm{O}_{2}$ gas is also crucial in many industrial processes and technological applications, ranging from combustion and steel-making processes (at high $\mathrm{O}_{2}$ concentrations) to food preparation (e.g. monitoring leaks of $\mathrm{O}_{2}$ at ppm levels). ${ }^{2}$ Potentiometric semiconductor sensors are commonly used for oxygen detection due to their many advantages (e.g. low cost, robustness, compact sizes), however, their narrow dynamic ranges and high operation temperatures severely limit their applications. ${ }^{3}$ Thin-film luminescent oxygen sensors offer promising but limited trace-concentration detection. ${ }^{4}$ As a result, amperometric gas sensors (AGSs) are still relevant to this day due the wider linear response range that they offer. ${ }^{2,5}$ For oxygen sensing, platinum $(\mathrm{Pt})$ is widely regarded as the most active electrode material. ${ }^{1,6}$

Room temperature ionic liquids (RTILs) have attracted considerable attention as solvents for electrochemical experiments. $^{7-9}$ RTILs are salts that are liquid at room temperature, possessing extremely low volatility and high intrinsic conductivity, in addition to other favorable properties as an electrochemical solvent. The application of RTILs as solvents in gas sensors has been extensively investigated, ${ }^{10-13}$ with suggestions for their use in membrane-free AGSs for a wide range of gases. ${ }^{10}$ RTILs have been recently combined with screen-printed electrodes (SPEs) to produce planar, low-cost, miniaturized sensing surfaces. These SPEs consist of three thick-film electrodes (working, reference and counter) printed onto a planar surface, with typical film thicknesses in the range 20-100 $\mu \mathrm{m}^{14}$. The detection of ammonia, ${ }^{15}$ oxygen, ${ }^{16-18}$ chlorine, ${ }^{19}$ methylamine $^{20}$ and hydrogen chloride ${ }^{20}$ gases on commercially-available SPEs in RTILs has been reported. Whereas the electrochemical reaction mechanisms of most gases (i.e. ammonia, chlorine, methylamine and hydrogen chloride) on SPEs was found to be similar to that conventional metal disk electrodes, unusual voltammetry of the $\mathrm{O}_{2} / \mathrm{O}_{2}{ }^{\circ-}$ redox couple in imidazolium RTILs on Pt SPEs was observed. ${ }^{16}$ Cyclic voltammograms exhibited a cross-over characteristic and an absence of the superoxide oxidation peak, which together suggested a reaction of superoxide with the paste of the Pt SPE. Although linear calibration graphs were obtained $\left(\mathrm{R}^{2}>0.99\right)$, the 
follow-up chemical reactions suggested that these SPE/RTIL systems may only be suitable for "singleuse” $\mathrm{O}_{2}$ detection. ${ }^{16}$ In contrast, CVs performed in an aprotic pyrrolidinium based RTIL were comparable to those on standard Pt macrodisk electrodes. ${ }^{16}$

We have recently found that mechanical polishing of Pt-SPEs produced a superior electrochemical performance in aqueous electrolyte media compared to other, more conventional electrode surface treatments. $^{21}$ In this paper, we therefore investigate the effect of mechanical polishing of Pt-SPEs for the detection of oxygen in two RTILs. Particular focus is given to the RTIL 1-ethyl-3-methylimidazolium bis(trifluoromethylsulfonyl)imide $\left(\left[\mathrm{C}_{2} \mathrm{mim}\right]\left[\mathrm{NTf}_{2}\right]\right)$, where non-ideal voltammetry for the $\mathrm{O}_{2} / \mathrm{O}_{2}{ }^{--}$redox couple was observed on unpolished Pt-SPEs. ${ }^{16}$ The electrodes are subjected to extended monitoring of oxygen using cyclic voltammetry and the harsher technique of long-term chronoamperometry, where superoxide is continuously generated at the electrode. The results presented here clearly show that mechanical polishing improves the performances of Pt-SPEs for prolonged oxygen sensing in RTILs.

\section{Experimental}

\subsection{Chemical Reagents}

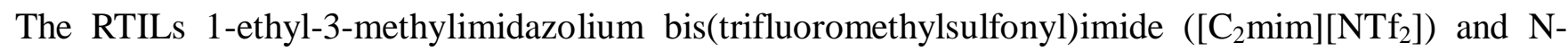

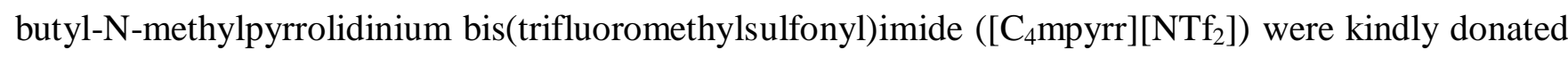
by the group of Professor Christopher Hardacre at Queens University, Belfast, synthesized and purified according to standard literature procedures. ${ }^{22,23}$ They were used as received, without any additional drying or purification procedures. Acetonitrile (MeCN 99.8\%, Sigma-Aldrich Pty Ltd., NSW, Australia), ethanol (EtOH, Sigma-Aldrich, 99\%), and ultrapure water (with a resistance of $18.5 \mathrm{M} \Omega \cdot \mathrm{cm}$ prepared by a Milli-Q laboratory water purification system (Millipore Pty Ltd., North Ryde, NSW, Australia) were used for rinsing the electrodes after polishing. High-purity oxygen gas $\left(\mathrm{O}_{2},>99.5 \%\right)$ and high-purity nitrogen gas $\left(\mathrm{N}_{2}, 99.99 \%\right)$ were purchased from BOC gases (North Ryde, NSW, Australia). Tetrahydrofuran (THF, Sigma-Aldrich, 99\%) was used to remove the polymer coating of the 
Pt-SPEs prior to polishing. 0.5 M sulfuric acid ( $\mathrm{H}_{2} \mathrm{SO}_{4(\mathrm{aq})}$, Ajax Finechem, WA, Australia), and $0.1 \mathrm{M}$ potassium chloride (KCl, > 99.5\%, Fluka, Buchs, Switzerland) aqueous (aq) solutions were prepared using ultrapure water.

\subsection{Preparation of polished Pt-SPEs}

Pt-SPEs from DropSens (DRP-550, Oviedo, Spain) were chosen due to their reportedly better electrochemical performance and reproducibility compared to other commercially available SPEs. ${ }^{24,25}$ The Pt-SPEs consist of a 4mm diameter Pt based working electrode (WE), a Pt based counter electrode (CE), and a silver based (quasi-) reference electrode (RE). Unpolished SPEs have the following estimated geometric areas: $\mathrm{WE}=12.6 \mathrm{~mm}^{2}, \mathrm{CE}=12.0 \mathrm{~mm}^{2}$ and $\mathrm{RE}=1.83 \mathrm{~mm}^{2}$. Polished SPEs have the same WE area, but $\mathrm{CE}=17.9 \mathrm{~mm}^{2}$ and $\mathrm{RE}=4.7 \mathrm{~mm}^{2}$. Areas were estimated from optical images, and the larger CE and RE for polished SPEs is due to the additional electrode area exposed after the removal of the polymer mask. The Pt-SPEs were soaked and sonicated in THF (to remove the blue polymer material), followed by polishing on soft lapping pads on a rotating mechanical polisher at a rotation speed of 600 rpm for ca. 1 minute, until a glossy finish was obtained. The exposed Ag metal traces were then sealed with SELLEYS ${ }_{\circledast}$ Silicone Sealant (100\% Silicone, purchased from local hardware store) to leave only the three electrode surfaces (WE, CE and RE) uncovered. Unless otherwise stated, the unpolished Pt-SPEs were used 'as-is' straight out of the box without subjecting to any pre-treatment.

\subsection{Electrochemical experiments}

Pt-SPEs were connected via soldered wires to a $\mu$-Autolab Type III potentiostat (Eco-Chemie, Netherlands) controlled by a PC running NOVA 1.8 software. The step potential for CV experiments was fixed at $0.003 \mathrm{~V}$ and a scan rate of $0.1 \mathrm{~V} \cdot \mathrm{s}^{-1}$ was consistently used. $30 \mu \mathrm{L}$ of RTIL was dropcasted over the three electrodes for each experiment. The Pt-SPE was then inserted into a specially designed glass cell for gas sensing experiments. ${ }^{16}$ Oxygen gas was introduced from a cylinder, and was further diluted with nitrogen gas, as detailed previously. ${ }^{16}$ A total gas flow rate of 100 standard cubic 
centimeters (sccm) was used for all the CV experiments. The RTIL was flushed with nitrogen for ca. 1 hour before commencing experiments in order to remove dissolved impurities such as oxygen and water naturally present in RTILs exposed to air. No obvious voltammetric features were observed in the blanks, suggesting that no significant impurities are present (e.g. water/unreacted starting materials). ${ }^{26}$ This is important, especially as water and other impurities can affect the kinetics of reactions ${ }^{27}$ and the mechanism of the ORR. ${ }^{28}$ Before CVs of oxygen were recorded, consecutive CVs (from 0 to $-1.8 \mathrm{~V}$ ) were performed in a $\mathrm{N}_{2}$-purged environment until the voltammetry stabilized (typically up to 12 cycles). After each $\mathrm{CV}$ of oxygen, 8 minutes was allowed before the commencement of the next scan for replenishment of the oxygen content of the RTIL.

Prolonged chronoamperometry experiments, referred to here as long-term chronoamperometry (LTCA), were conducted after $120 \mathrm{CV}$ cycles in the presence of $100 \%$ vol. $\mathrm{O}_{2}$. The $\mathrm{O}_{2}$ concentrations were varied between 0 and $5 \%$ vol. (in the gas phase) with respect to $\mathrm{N}_{2}$ carrier gas. The actual concentrations measured by CV or LTCA are those in the RTIL phase, and are dependent on the degree of partitioning of the gas from the gas phase to the liquid phase. The data was collected at $15 \mathrm{~s}$ time intervals with an overpotential of $200 \sim 300 \mathrm{mV}$ relative to the $\mathrm{CV}$ peak for $\mathrm{O}_{2}$ reduction. The response was allowed to stabilize (under $\mathrm{N}_{2}$ ) for at least 30 mins before the introduction of $\mathrm{O}_{2}$ gas. To ensure faster displacement of the previous concentration of oxygen within the cell, a higher total flow rate of 1000 sccm was used during the amperometric experiments. The cell was flushed with $\mathrm{N}_{2}$-gas between each change of $\mathrm{O}_{2}$-concentration, following which sufficient time (up to 50 mins) was allowed for baseline stabilization.

Electrochemical activation of Pt-SPEs was carried out using a separate Pt-wire coil counter electrode and a Ag/AgCl reference electrode (BASi, West Lafayette, IN, USA). Pt-SPEs were subjected to $30 \mathrm{CV}$ cycles between $1.25 \mathrm{~V}$ and $-0.25 \mathrm{~V}$ (vs. Ag/AgCl) at a scan rate of $1 \mathrm{Vs}^{-1}$, in either $0.5 \mathrm{M}$ $\mathrm{H}_{2} \mathrm{SO}_{4(\mathrm{aq})}{ }^{29}$ or $0.5 \mathrm{M} \mathrm{KCl}_{(\mathrm{aq})}{ }^{30}$. 


\section{Results and Discussion}

\subsection{Consecutive $\mathrm{CVs}$ for $\mathrm{O}_{2}$ reduction on unpolished and polished Pt-SPEs}

Polished and unpolished Pt-SPEs were subjected to 120 repeated cyclic voltammetry (CV) scans under $100 \%$ vol. $\mathrm{O}_{2}$ flow, to enable the comparison of the effect of polishing on the short- and long-term performance of Pt-SPE/RTIL systems for $\mathrm{O}_{2}$ sensing. Two RTILs were studied: [ $\mathrm{C}_{2}$ mim] $\left[\mathrm{NTf}_{2}\right]$, which provides the highest diffusion coefficient for $\mathrm{O}_{2}{ }^{10}$ amongst the available RTILs, and $\left[\mathrm{C}_{4} \mathrm{mpyrr}\right]\left[\mathrm{NTf}_{2}\right]$, which provides the best voltammetric response for $\mathrm{O}_{2}$ on Pt-SPEs amongst eight RTILs tested in our previous work. ${ }^{16}$

Figure 1 shows CVs of the $\mathrm{O}_{2} / \mathrm{O}_{2}{ }^{--}$redox couple in $\left[\mathrm{C}_{2} \mathrm{mim}\right]\left[\mathrm{NTf}_{2}\right]$ and $\left[\mathrm{C}_{4} \mathrm{mpyrr}\right]\left[\mathrm{NTf}_{2}\right]$ on both unpolished and polished Pt-SPEs. 120 consecutive cycles were performed in the presence of $100 \%$ vol. $\mathrm{O}_{2}$, with a wait time of 8 minutes between scans to allow for replenishment of depleted $\mathrm{O}_{2}$. The $1^{\text {st }}, 2^{\text {nd }}$ and $120^{\text {th }}$ cycles are overlaid in the main figure, with the initial blank under $\mathrm{N}_{2}$ shown as dotted lines. The $120^{\text {th }}$ cycle (with the blank also subjected to $120 \mathrm{CV}$ cycles) is presented individually in the inset. In $\left[\mathrm{C}_{2} \mathrm{mim}\right]\left[\mathrm{NTf}_{2}\right]$ on an unpolished electrode (Figure 1a), chemically irreversible voltammetry was observed (i.e. no superoxide oxidation peak), with the appearance of a 'cross-over' of current in the forward and reverse scans on the second cycle, consistent with that reported previously. ${ }^{16}$ This was proposed to be due to the reaction of the electrogenerated superoxide with components of the ink matrix in the mildly acidic imidazolium RTIL; ${ }^{16}$ the cross-over likely occurs as a result of the changing nature of the working electrode during the course of a CV cycle, due to that reaction. Once the components of the ink are consumed, the reaction no longer proceeds and the crossover is not present (typically after ca. 35-40 scans in the presence of $100 \%$ vol. $\mathrm{O}_{2}$ ). The reaction of superoxide with the imidazolium cation has been previously suggested by AlNashef et al. ${ }^{31}$ and Islam et al. ${ }^{32}$ Later, Frith et al. ${ }^{33}$ used insitu Raman spectroscopy to prove the degradation of $\left[\mathrm{C}_{2} \mathrm{mim}\right]\left[\mathrm{NTf}_{2}\right]$ by superoxide attack. Importantly, the degradation of $\left[\mathrm{C}_{4}\right.$ mpyrr $]\left[\mathrm{NTf}_{2}\right]$ was not observed in their work, ${ }^{33}$ as is consistent with our results. ${ }^{16}$ However, in our case, it appears that the compounds in the paste of the screen-printed ink are linked to the degradation of $\left[\mathrm{C}_{2} \mathrm{mim}\right]^{+}$observed within the voltammetric timescale. ${ }^{16}$ 
Figure 1a also shows a ca. $600 \mathrm{mV}$ shift in the reduction peak potential from the first to the second scan, as reported previously. ${ }^{16}$ This is mainly due to a shift in the quasi-reference electrode potential, as a similar potential shift was observed for the ferrocene/ferrocenium redox couple when added in-situ. ${ }^{21}$ In $\left[\mathrm{C}_{4}\right.$ mpyrr] $\left[\mathrm{NTf}_{2}\right]$, the voltammetry on the unpolished electrode (Figure 1c) is more chemically reversible (the superoxide oxidation peak is clearly seen, as reported previously). ${ }^{16}$ However, the $\mathrm{CV}$ has a less ideal shape compared to $\mathrm{O}_{2}$ reduction on macrodisk electrodes ${ }^{16}$ and varies slightly from the first to the second scan. The peak current is smaller in $\left[\mathrm{C}_{4} \mathrm{mpyrr}\right]\left[\mathrm{NTf}_{2}\right]$ compared to $\left[\mathrm{C}_{2} \mathrm{mim}\right]\left[\mathrm{NTf}_{2}\right]$ probably due to differences in the diffusion coefficient and solubility of $\mathrm{O}_{2}$ in the two RTILs.

Continued cycling on unpolished Pt-SPEs in $\left[\mathrm{C}_{2} \mathrm{mim}\right]\left[\mathrm{NTf}_{2}\right]$ leads to deterioration in the voltammetry, with the growth of additional peaks in the cathodic scan (Figure 1a inset). The identities of these peaks are currently unclear, but are thought to be due to the build-up of reaction products of the ink binding materials with superoxide in the presence of $\left[\mathrm{C}_{2} \mathrm{mim}\right]\left[\mathrm{NTf}_{2}\right]$. A significantly smaller but still noticeable degradation was observed on unpolished SPEs in $\left[\mathrm{C}_{4} \mathrm{mpyrr}\right]\left[\mathrm{NTf}_{2}\right]$ after 120 cycles (Figure 1c inset). It is noted that there was some variability in the peak shapes on unpolished SPEs (from 5 samples in the same batch) and not every SPEs gave exactly the same CV responses after 120 cycles.

However, in both RTILs, CVs on polished Pt-SPEs were much improved. In $\left[\mathrm{C}_{2} \mathrm{mim}\right]\left[\mathrm{NTf}_{2}\right]$ (Figure 1b), the reduction peak potential did not shift between the first and second scans, suggesting a more stable quasi-reference electrode surface after polishing. However, potential shifting was observed on all electrodes over the course of 120 scans which means that instability in the reference electrode still persists after polishing. Additionally, peak currents were smaller than on unpolished Pt-SPEs, which could imply a reduction in the number of electrons exchanged or a change in the electrode surface area. $^{21}$ After 120 cycles (Figure 1b inset), the voltammetry resembled that of an ideal CV for oxygen reduction (e.g. on an polished macrodisk electrode). ${ }^{16}$ The currents are also significantly smaller, suggesting the number of electrons involved in the reduction step is lower (estimated here to be $n=1$, 
based on the wave-shape and the known oxygen voltammetry in RTILs on conventional Pt disk electrodes). ${ }^{16,34}$ The generation of this 'ideal' $\mathrm{CV}$ wave-shape for the $\mathrm{O}_{2} / \mathrm{O}_{2}{ }^{\circ-}$ redox couple in $\left[\mathrm{C}_{2} \mathrm{mim}\right]\left[\mathrm{NTf}_{2}\right]$ simply by polishing is remarkable. For $\left[\mathrm{C}_{4} \mathrm{mpyrr}\right]\left[\mathrm{NTf}_{2}\right]$ (Figure $1 \mathrm{~d}$ ), the wave-shapes

for all CVs from the first to $120^{\text {th }}$ cycles showed chemically reversible behavior with similar peak currents and were much more stable over time, suggesting suitability for long-term measurements (although possible reference potential shifting over time would have to be accounted for). The most likely explanation for the improved behavior with polishing is the exposure of a fresh screen-printed Pt material by the removal of surface contaminants (e.g. excess residual binding materials or absorbed organic oils from the manufacturing and packaging processes). ${ }^{21}$

Attempts were also made to electrochemically activate the Pt-SPEs (both polished and unpolished) using conventional methods by cycling in $0.5 \mathrm{M} \mathrm{H}_{2} \mathrm{SO}_{4}(\mathrm{aq})^{29}$ and $0.5 \mathrm{M} \mathrm{KCl}^{30}$. However, the CVs for oxygen reduction on both polished and unpolished electrodes were highly unusual, showing larger background currents and poorly shaped peaks. This demonstrates that these methods are unsuitable for the activation of Pt-SPEs for use with RTILs in $\mathrm{O}_{2}$ gas-sensing experiments.

\subsection{Analytical response of unpolished and polished Pt-SPEs}

To assess the advantages of using polished Pt-SPEs for extensive continuous $\mathrm{O}_{2}$ gas monitoring, $\mathrm{CV}$ and LTCA at different concentrations of oxygen were performed after the electrodes had been subjected to $120 \mathrm{CV}$ cycles in the presence of $100 \%$ vol. $\mathrm{O}_{2}$.

\subsubsection{Cyclic Voltammetry}

Figure 2 shows $\mathrm{CVs}$ of the $\mathrm{O}_{2} / \mathrm{O}_{2}{ }^{--}$redox couple at various concentrations $\left(0-100 \%\right.$ vol. $\left.\mathrm{O}_{2}\right)$ in both $\left[\mathrm{C}_{2} \mathrm{mim}\right]\left[\mathrm{NTf}_{2}\right]$ and $\left[\mathrm{C}_{4} \mathrm{mpyrr}\right]\left[\mathrm{NTf}_{2}\right]$ on unpolished and polished Pt-SPEs. In $\left[\mathrm{C}_{2} \mathrm{mim}\right]\left[\mathrm{NTf}_{2}\right]$ on an unpolished SPE (Figure 2a), contaminant peaks are evident even in the absence of oxygen (dotted line). These were not present initially in the blank CVs in Figure 1, and even after $120 \mathrm{CV}$ cycles in the absence of superoxide (insets to Figure 2). This suggests that they have built-up during 120 cycles as a 
result of electrochemically-generated products of the superoxide/SPE paste/RTIL reaction. As the oxygen concentration is increased, the peak current at ca. -1.3 to $-1.6 \mathrm{~V}$ also increased. For all other SPE/RTIL systems, reasonable single-peak CVs were observed, with the oxygen reduction current increasing with concentration. For all other SPEs, single-peak CVs were observed, with the oxygen reduction currents increasing with concentration. Figures $2 \mathrm{~b}$ and $2 \mathrm{c}$ show the presence of a small prepeak before the onset of oxygen reduction, however this is not present in Figure 2d (polished SPE in $\left.\left[\mathrm{C}_{4} \mathrm{mpyrr}\right]\left[\mathrm{NTf}_{2}\right]\right)$, despite already being subjected to $120 \mathrm{CV}$ cycles in $100 \% \mathrm{vol}$. $\mathrm{O}_{2}$. The insets to Figure 2 show plots of background-subtracted reduction current vs. oxygen concentration. For Figure 2a, the currents of the largest peak at potentials of ca. -1.3 to $-1.6 \mathrm{~V}$ were used to construct the calibration graph. Despite the presence of additional contaminant peaks in Figure 2a, a linear correlation was still obtainable at high concentrations (with large standard deviations), however the plot diverged from linearity at lower concentrations. All other plots were linear $\left(R^{2}>0.99\right)$. The equations for the lines of best-fit and corresponding limits of detection (LODs, based on 3 standard deviations of the regression) are presented in Table 1 , along with the peak-to-peak separations $\left(\Delta E_{\mathrm{p}}\right)$ for the $\mathrm{O}_{2} / \mathrm{O}_{2}{ }^{--}$redox couple, averaged over the concentrations $10-100 \%$ vol. $\mathrm{O}_{2}$.

The LOD in $\left[\mathrm{C}_{2} \mathrm{mim}\right]\left[\mathrm{NTf}_{2}\right]$ was significantly improved on polished Pt-SPEs $\left(12.5 \%\right.$ vol. $\left.\mathrm{O}_{2}\right)$ compared to unpolished SPEs (23.0\% vol. $\left.\mathrm{O}_{2}\right)$, but remains too high for most analytical applications. However, in $\left[\mathrm{C}_{4}\right.$ mpyrr $]\left[\mathrm{NTf}_{2}\right]$ the performance was significantly better than in $\left[\mathrm{C}_{2} \mathrm{mim}\right]\left[\mathrm{NTf}_{2}\right]$, with LODs of 0.82 and $0.78 \%$ vol. $\mathrm{O}_{2}$ on unpolished and polished SPEs, respectively. The $\Delta E_{\mathrm{p}}$ values also showed a substantial improvement on polished electrodes, suggesting either faster kinetics or lower resistance on polished electrodes after long-term cycling. These results demonstrate a significant advantage of using polished Pt-SPEs to improve $\mathrm{O}_{2}$ sensing performance in RTILs, particularly in $\left[\mathrm{C}_{2} \mathrm{mim}\right]\left[\mathrm{NTf}_{2}\right]$

\subsubsection{Long-term Chronoamperometry}

Figure 3 shows the LTCA response for different concentrations of $\mathrm{O}_{2}$ (descending from 5 to $0.1 \%$ vol. and ascending back up to $5 \%$ in (a) $\left[\mathrm{C}_{2} \mathrm{mim}\right]\left[\mathrm{NTf}_{2}\right]$ and (b) $\left[\mathrm{C}_{4} \mathrm{mpyrr}\right]\left[\mathrm{NTf}_{2}\right]$ on unpolished and 
polished Pt-SPEs. The potential was held at a suitable overpotential relative to the oxygen reduction peak and the current was monitored over time. $100 \%$ vol. $\mathrm{N}_{2}$ gas was used between each oxygen concentration to observe any change in the baseline currents. Higher concentrations than $5 \%$ vol. $\mathrm{O}_{2}$ were avoided in these experiments due to the very rapid deterioration in the current response (results not shown) and the observation of a brown-colored product building up in the RTIL. This deterioration was observed for both unpolished and polished Pt-SPEs, even when the Pt-SPE was not subjected to the initial $120 \mathrm{CV}$ cycles. In contrast, Pt-SPEs exposed only to nitrogen did not show any indication of baseline changes or deterioration. It should be noted that long-term constant biasing is considered a much harsher experiment compared to $\mathrm{CV}$ (or short-term chronoamperometry) due to the constant generation and accumulation of superoxide at the WE. Thus, CV may be a better method for monitoring $\mathrm{O}_{2}$ at concentrations higher than $5 \%$ vol.

As seen in Figure 3a, in $\left[\mathrm{C}_{2} \mathrm{mim}\right]\left[\mathrm{NTf}_{2}\right]$, the current axis has been shifted for the unpolished electrode (dotted line) to allow for a better comparison to the polished electrode (solid line). The results show that the unpolished Pt-SPE in $\left[\mathrm{C}_{2} \mathrm{mim}\right]\left[\mathrm{NTf}_{2}\right]$ is much less responsive to $\mathrm{O}_{2}$ concentrations than a polished Pt-SPE, with a large and increasing background current. This suggests a continuous change of the background signal, perhaps by the accumulation of electrogenerated products at the working electrode, which is unsurprising given the unusual CV on this electrode (inset, Figure 1a). There is also a noticeable background current in $\left[\mathrm{C}_{4} \mathrm{mpyrr}\right]\left[\mathrm{NTf}_{2}\right]$ on an unpolished electrode (Figure 3b, dotted line). Although a response to different concentrations of $\mathrm{O}_{2}$ is still appreciable above the background, the current transient is far from ideal, which makes analysis difficult. In contrast, for both RTILs on polished SPEs, the chronoamperometric transient is better with larger and well-defined current responses above background at different concentrations. In $\left[\mathrm{C}_{2} \mathrm{mim}\right]\left[\mathrm{NTf}_{2}\right]$ on polished SPEs, the baseline is still observed to vary appreciably over time. This could be due to build-up of a contaminant product as indicated by the small pre-peak in the voltammetry (Figure 2b). The baseline is more stable in $\left[\mathrm{C}_{4} \mathrm{mpyrr}\right]\left[\mathrm{NTf}_{2}\right]$ on polished SPEs, where a more "ideal” CV shape was observed (Figure 2d). 
Figure 4 shows the calibration graphs for the LTCA experiments on polished SPEs presented in Figure 3. Both the 'ascending' and 'descending' concentration plots are shown, with their lines of best fit. Each concentration response was taken at the current plateau, or at the peak in cases where the current did not reach a plateau. The background currents for each $\mathrm{O}_{2}$ concentration were measured just prior to the introduction of oxygen. There appears to be a difference in the gradients for the 'descending' and 'ascending' plots in $\left[\mathrm{C}_{2} \mathrm{mim}\right]\left[\mathrm{NTf}_{2}\right]$. It is further observed in Figure 3a that the decline of the current response after reaching a peak becomes more severe over time and as a result of exposure to higher $\mathrm{O}_{2}$ concentrations. The equations of the calibration graphs and the corresponding limits of detection are presented in Table 2.

As seen in Table 2, the sensitivity is higher in $\left[\mathrm{C}_{2} \mathrm{mim}\right]\left[\mathrm{NTf}_{2}\right]$ compared to $\left[\mathrm{C}_{4} \mathrm{mpyrr}\right]\left[\mathrm{NTf}_{2}\right]$, probably due to the lower viscosity and faster partitioning of $\mathrm{O}_{2}$ gas into $\left[\mathrm{C}_{2} \mathrm{mim}\right]\left[\mathrm{NTf}_{2}\right]$. The sensitivities in both RTILs from LTCA (Table 2) were worse than those from CV (Table 1), but the LODs were better. However, it is noted that the concentration range chosen for the two studies were different (0.1-5 \% vol. for LTCA and 10-100 \% vol. for CV). The choice of concentration ranges was based on the lowest $\mathrm{O}_{2}$ concentration that was detectable via $\mathrm{CV}$, and the instability of the response at higher concentrations during LTCA.

The $90 \%$ response times, $t_{90}$ (defined as the time taken to reach $90 \%$ of the plateau current from the baseline), were also estimated from Figure 3. The relatively slow response times ( $\left.t_{90}\right)$ of ca. 3.5 mins for $\left[\mathrm{C}_{2} \mathrm{mim}\right]\left[\mathrm{NTf}_{2}\right]$ and ca. 5 mins for $\left[\mathrm{C}_{4} \mathrm{mpyrr}\right]\left[\mathrm{NTf}_{2}\right]$ on polished Pt-SPEs are probably due to the large volume (30 $\mu \mathrm{L})$ of RTIL used. This was necessary to ensure proper coverage of the exposed area of the three electrode surfaces, particularly on polished SPEs. It is expected that the response time could be improved with a smaller volume (e.g. thinner layers) of RTIL solvent.

\subsection{Recovery of 'fouled' Pt-SPE surfaces by polishing}

Figure 5 illustrates the recovery of an unpolished Pt-SPE surface that has been fouled by extensive consecutive CV (i.e. 120 cycles in the presence $100 \%$ vol. $\mathrm{O}_{2}$ ) in $\left[\mathrm{C}_{4} \mathrm{mpyrr}\right]\left[\mathrm{NTf}_{2}\right]$. The dotted line is 
the CV response of the fouled Pt-SPE, clearly showing non-ideal voltammetry, with a reductive prepeak (at ca. -1.1 V) and a follow-up oxidation peak (at ca. -0.1 V) present. When the RTIL was rinsed off and replaced with a fresh aliquot, the CV shape changed significantly and did not recover (dashed line). However, polishing the fouled SPE recovered the CV to one resembling a typical reversible $\mathrm{O}_{2} / \mathrm{O}_{2}{ }^{--}$redox couple (solid line). The Pt-SPE could be successfully re-polished more than 12 times before the screen printed platinum surface became visually worn out and the typical $\mathrm{O}_{2}$ voltammetry in $\left[\mathrm{C}_{4} \mathrm{mpyrr}\right]\left[\mathrm{NTf}_{2}\right]$ was unachievable. The number of times that a SPE can withstand repeated re-polishing is dependent on various factors, such as the extent (i.e. pressure and duration) of the initial and subsequent polishing. Additional unidentified peaks occasionally appeared after re-polishing, but a stable voltammogram is achieved after only a few cycles (i.e. $<3$ ) in the presence of $100 \%$ vol. $\mathrm{O}_{2}$. The results show that SPEs, typically marketed as single-use devices, can be reused multiple times by simply polishing the surface.

\section{Conclusions}

The long-term sensing of $\mathrm{O}_{2}$ gas in two RTILs on platinum SPEs before and after mechanical polishing has been studied. Polishing provides a substantial improvement in the voltammetric wave-shapes and stabilities when subjected to prolonged repeated scanning. In particular for $\left[\mathrm{C}_{2} \mathrm{mim}\right]\left[\mathrm{NTf}_{2}\right]$, where the behavior is less than ideal on an unpolished electrode, the cross-over characteristic was removed simply by polishing, and eventually evolved to a voltammetric characteristic resembling that on a typical platinum macrodisk electrode. This is in contrast to the severe degradation that was observed on unpolished Pt-SPEs. There was also appreciable improvement in the $\mathrm{CV}$ response for $\mathrm{O}_{2} / \mathrm{O}_{2}{ }^{--}$in $\left[\mathrm{C}_{4} \mathrm{mpyrr}\right]\left[\mathrm{NTf}_{2}\right]$ after polishing. Analytical responses for unpolished and polished Pt-SPEs were examined using both CV and LTCA at different $\mathrm{O}_{2}$ concentrations, with the lowest LODs observed on polished electrodes in $\left[\mathrm{C}_{4}\right.$ mpyrr $]\left[\mathrm{NTf}_{2}\right]$, but the highest sensitivities on polished electrodes in $\left[\mathrm{C}_{2} \mathrm{mim}\right]\left[\mathrm{NTf}_{2}\right]$. Overall, we have shown that polishing is a simple and highly effective pre-treatment method for Pt-SPEs, and can be used to re-vitalize fouled Pt-SPEs (generally regarded as single-use 
electrodes) multiple times. This provides a method to extend the reusability and lifetime of SPEs in lowcost $\mathrm{O}_{2}$ sensors based on Pt-SPE/RTIL systems and for other analytical applications.

\section{Acknowledgements}

The authors thank Professor Christopher Hardacre at Queens University Belfast for the kind donation of the ionic liquids used in this work. DSS thanks the Australian Research Council for a Discovery Early Career Researcher Award (DECRA: DE120101456). JL acknowledges PhD funding through an Australian Postgraduate Award and a Curtin Research Scholarship. 


\section{Tables}

Table 1. Analytical performances by CV of Pt-SPEs in RTILs; equations for the linear calibration graphs presented in Figure 2, and corresponding limits of detection (LODs) for unpolished and polished Pt-SPEs. Also given are the peak-to-peak separations $\left(\Delta E_{\mathrm{p}}\right)$ for the $\mathrm{O}_{2} / \mathrm{O}_{2}{ }^{-}$redox couple, averaged over all concentrations (10-100 \% vol. $\mathrm{O}_{2}$ ). The electrodes were subjected to $120 \mathrm{CV}$ cycles before recording calibration data.

\begin{tabular}{cccccc}
\hline \multirow{2}{*}{ RTIL } & Treatment & $\begin{array}{c}\text { Calibration Equation } \\
\left.\text { (where } I / \mathrm{A} \text { and }\left[\mathrm{O}_{2}\right] / \% \text { vol. }\right)\end{array}$ & $\mathrm{R}^{2}$ & LOD / \% vol. & $\Delta E_{\mathrm{p}} / \mathrm{mV}$ \\
\hline \multirow{2}{*}{$\mathrm{C}_{2}$ mim] $]\left[\mathrm{NTf}_{2}\right]$} & Unpolished & $-I=9.0 \times 10^{-7}\left[\mathrm{O}_{2}\right]+3.6 \times 10^{-5}$ & 0.9537 & 23.0 & - \\
& Polished & $-I=1.0 \times 10^{-6}\left[\mathrm{O}_{2}\right]+1.3 \times 10^{-5}$ & 0.9972 & 12.5 & $420 \pm 13$ \\
\hline \multirow{2}{*}{$\mathrm{C}_{4} \mathrm{mpyrr}^{2}\left[\mathrm{NTf}_{2}\right]$} & Unpolished & $-I=6.9 \times 10^{-7}\left[\mathrm{O}_{2}\right]+1.8 \times 10^{-6}$ & 0.9967 & 0.82 & $395 \pm 15$ \\
& Polished & $-I=7.3 \times 10^{-7}\left[\mathrm{O}_{2}\right]+4.6 \times 10^{-7}$ & 0.9999 & 0.78 & $266 \pm 10$ \\
\hline
\end{tabular}

Table 2. Analytical performances by LTCA of polished Pt-SPEs in RTILs; equations for the linear calibration graphs presented in Figure 4, and limits of detection (LODs), for the initial 'descending' and subsequent 'ascending' sequence of $\mathrm{O}_{2}$ concentrations from LTCA (after being subjected to $120 \mathrm{CV}$ cycles).

\begin{tabular}{ccccc}
\hline \multirow{2}{*}{ RTIL } & Order & $\begin{array}{c}\text { Calibration Equation } \\
\text { (where } I / \mathrm{A} \text { and }\left[\mathrm{O}_{2}\right] / \% \text { vol.) }\end{array}$ & $\mathrm{R}^{2}$ & $\begin{array}{c}\text { LOD / } \\
\% \text { vol. }\end{array}$ \\
\hline$\left[\mathrm{C}_{2} \mathrm{mim}\right]\left[\mathrm{NTf}_{2}\right]$ & Descending & $-I=2.7 \times 10^{-7}\left[\mathrm{O}_{2}\right]-3.1 \times 10^{-8}$ & 0.9978 & 0.28 \\
& Ascending & $-I=3.2 \times 10^{-7}\left[\mathrm{O}_{2}\right]-3.8 \times 10^{-9}$ & 0.9999 & 0.08 \\
\hline \multirow{2}{*}{$\mathrm{C}_{4} \mathrm{mpyrr}^{2}\left[\mathrm{NTf}_{2}\right]$} & Descending & $-I=1.1 \times 10^{-7}\left[\mathrm{O}_{2}\right]+4.5 \times 10^{-9}$ & 0.9954 & 0.13 \\
& Ascending & $-I=1.1 \times 10^{-7}\left[\mathrm{O}_{2}\right]+7.0 \times 10^{-9}$ & 0.9998 & 0.09 \\
\hline
\end{tabular}




\section{Figure. Legends}

Figure 1. Main Figures: Comparison of the $1^{\text {st }}$ (dashed), $2^{\text {nd }}$ (dot-dashed) and $120^{\text {th }}$ (solid) CV cycles of the $\mathrm{O}_{2} / \mathrm{O}_{2}{ }^{--}$redox couple with $100 \%$ vol. $\mathrm{O}_{2}$ in: $\left[\mathrm{C}_{2}\right.$ mim] $\left[\mathrm{NTf}_{2}\right]$ on (a) unpolished and (b) polished PtSPEs, and [ $\mathrm{C}_{4}$ mpyrr] $\left[\mathrm{NTf}_{2}\right]$ on (c) unpolished and (d) polished Pt-SPEs. The response in the absence of $\mathrm{O}_{2}$ is shown as a dotted line. Insets: Comparison of the $120^{\text {th }} \mathrm{CVs}$ (solid) with the blank (100\% $\mathrm{N}_{2}$, dots) also subjected to $120 \mathrm{CV}$ scans. Scan rate is $100 \mathrm{mVs}^{-1}$. The waiting time between consecutive scans was $8 \mathrm{~min}$. Potential shifting is due to the unstable reference electrode of the SPE, but the magnitude of the shift is smaller on the polished surface.

Figure 2. $\mathrm{CV}$ for $\mathrm{O}_{2}$ reduction in: $\left[\mathrm{C}_{2} \mathrm{mim}\right]\left[\mathrm{NTf}_{2}\right]$ on (a) an unpolished Pt-SPE and (b) a polished PtSPE, and in $\left[\mathrm{C}_{4}\right.$ mpyrr] $\left[\mathrm{NTf}_{2}\right]$ on (c) an unpolished Pt-SPE and (d) a polished Pt-SPE. Scan rate of $100 \mathrm{mVs}^{-1}$ at 10, 20, 40, 60, 80 and $100 \%$ vol. $\mathrm{O}_{2}$ after $120 \mathrm{CV}$ cycles in the presence of $100 \%$ vol. $\mathrm{O}_{2}$ was performed. The dotted lines are CVs in the absence of oxygen (after $120 \mathrm{CV}$ cycles in 100 $\%$ vol. $\mathrm{O}_{2}$ ). The insets are the corresponding plots of $\mathrm{O}_{2}$ reduction peak current (background corrected) vs. \% vol. $\mathrm{O}_{2}$ in the flow, and the line of best-fit. Error bars are represented as one standard deviation of three separate calibrations on different days. Where they are not clearly visible, the error bars are smaller than the symbol size.

Figure 3. LTCA at different $\mathrm{O}_{2}$ gas concentrations in (a) $\left[\mathrm{C}_{2} \mathrm{mim}\right]\left[\mathrm{NTf}_{2}\right]$ and (b) $\left[\mathrm{C}_{4} \mathrm{mpyrr}\right]\left[\mathrm{NTf}_{2}\right]$ on unpolished (dotted line) and polished (solid line) Pt-SPEs. The gas flow was alternated between $\mathrm{N}_{2}$ and varying concentrations of $\mathrm{O}_{2}$ in the following order: $5,4,3,2,1,0.5,0.3,0.1,0.3,0.5,1,3,5 \%$ vol. $\mathrm{O}_{2}$.

Figure 4. Plots of background corrected oxygen reduction currents vs. \% vol. $\mathrm{O}_{2}$, and the lines of bestfit for (a) $\left[\mathrm{C}_{2} \mathrm{mim}\right]\left[\mathrm{NTf}_{2}\right]$ and (b) $\left[\mathrm{C}_{4} \mathrm{mpyrr}\right]\left[\mathrm{NTf}_{2}\right]$ on polished Pt-SPEs, extracted from LTCA measurements presented in Figure 3. The solid lines (-) represent the linear regression for the first eight 'descending' oxygen concentrations (5, 4, 3, 2, 1, 0.5, 0.3, $0.1 \%$ vol.), and the dashed lines (- -) for the last six ‘ascending’ oxygen concentrations (0.1, 0.3, 0.5, 1, 3, 5 \% vol., see Figure 3).

Figure 5. Recovery of fouled Pt-SPE surfaces after polishing. The dotted line ( $\cdots$ ) shows CV of $100 \%$ $\mathrm{O}_{2}$ reduction on an unpolished Pt-SPE surface, degraded after long-term CV experiments (120 cycles) in $\left[\mathrm{C}_{4} \mathrm{mpyrr}\right]\left[\mathrm{NTf}_{2}\right]$. The dashed line (- -) shows the CV after the RTIL (visibly browned) was rinsed off and a fresh $30 \mu \mathrm{L}$ aliquot applied. The solid line (-) shows the CV after the RTIL was rinsed off, and the surface polished before applying a fresh $30 \mu \mathrm{L}$ aliquot of the RTIL. Scans were conducted with a scan rate of $100 \mathrm{mVs}^{-1}$. 

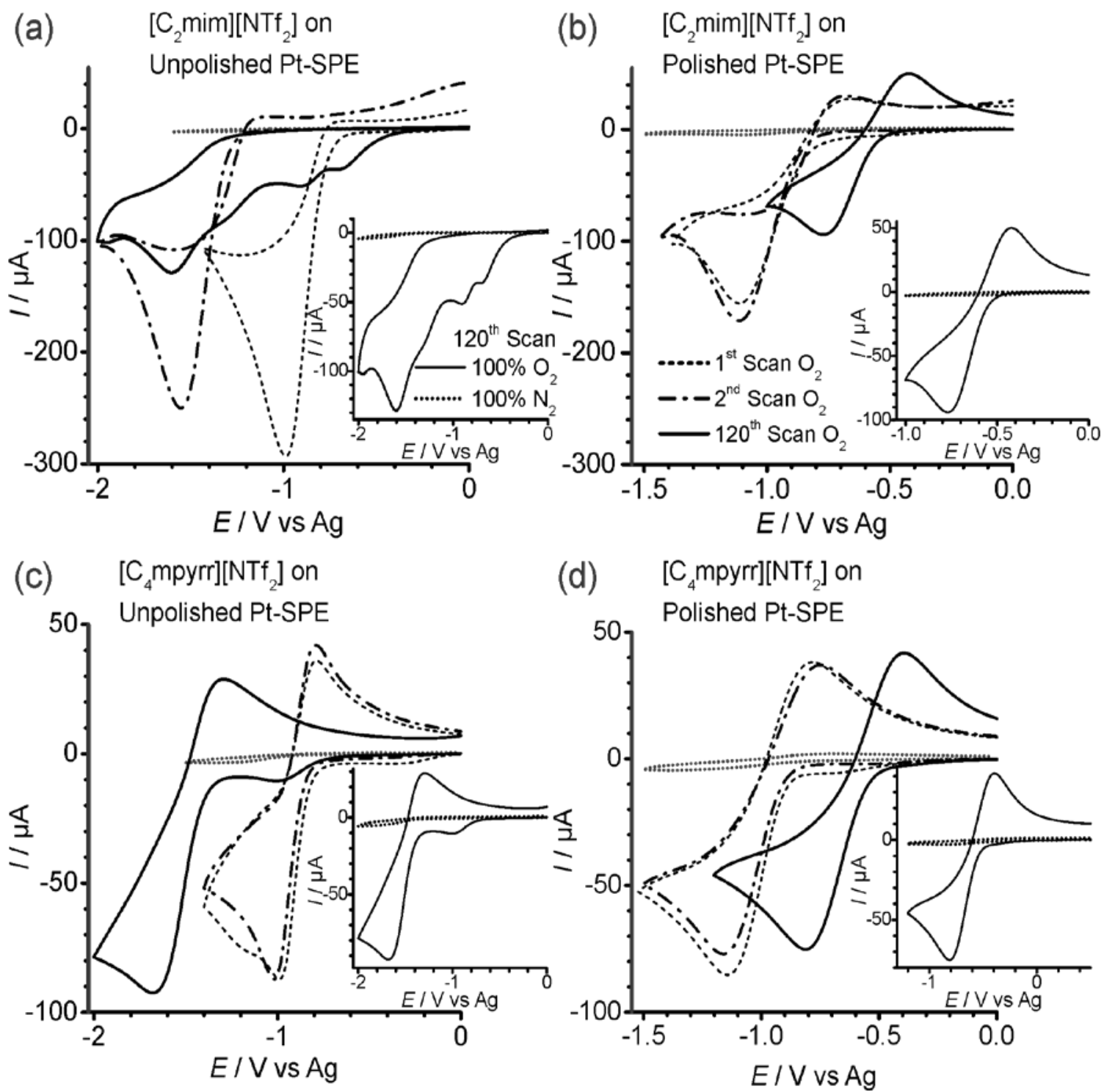

Figure 1. Main Figures: Comparison of the $1^{\text {st }}$ (dashed), $2^{\text {nd }}$ (dot-dashed) and $120^{\text {th }}$ (solid) CV cycles of the $\mathrm{O}_{2} / \mathrm{O}_{2}{ }^{--}$redox couple with $100 \%$ vol. $\mathrm{O}_{2}$ in: $\left[\mathrm{C}_{2}\right.$ mim] $\left[\mathrm{NTf}_{2}\right]$ on (a) unpolished and (b) polished Pt-SPEs, and $\left[\mathrm{C}_{4}\right.$ mpyrr $]\left[\mathrm{NTf}_{2}\right]$ on (c) unpolished and (d) polished Pt-SPEs. The response in the absence of $\mathrm{O}_{2}$ is shown as a dotted line. Insets: Comparison of the $120^{\text {th }} \mathrm{CVs}$ (solid) with the blank $\left(100 \% \mathrm{~N}_{2}\right.$, dots) also subjected to $120 \mathrm{CV}$ scans. Scan rate is $100 \mathrm{mVs}^{-1}$. The waiting time between consecutive scans was $8 \mathrm{~min}$. Potential shifting is due to the unstable reference electrode of the SPE, but the magnitude of the shift is smaller on the polished surface. 

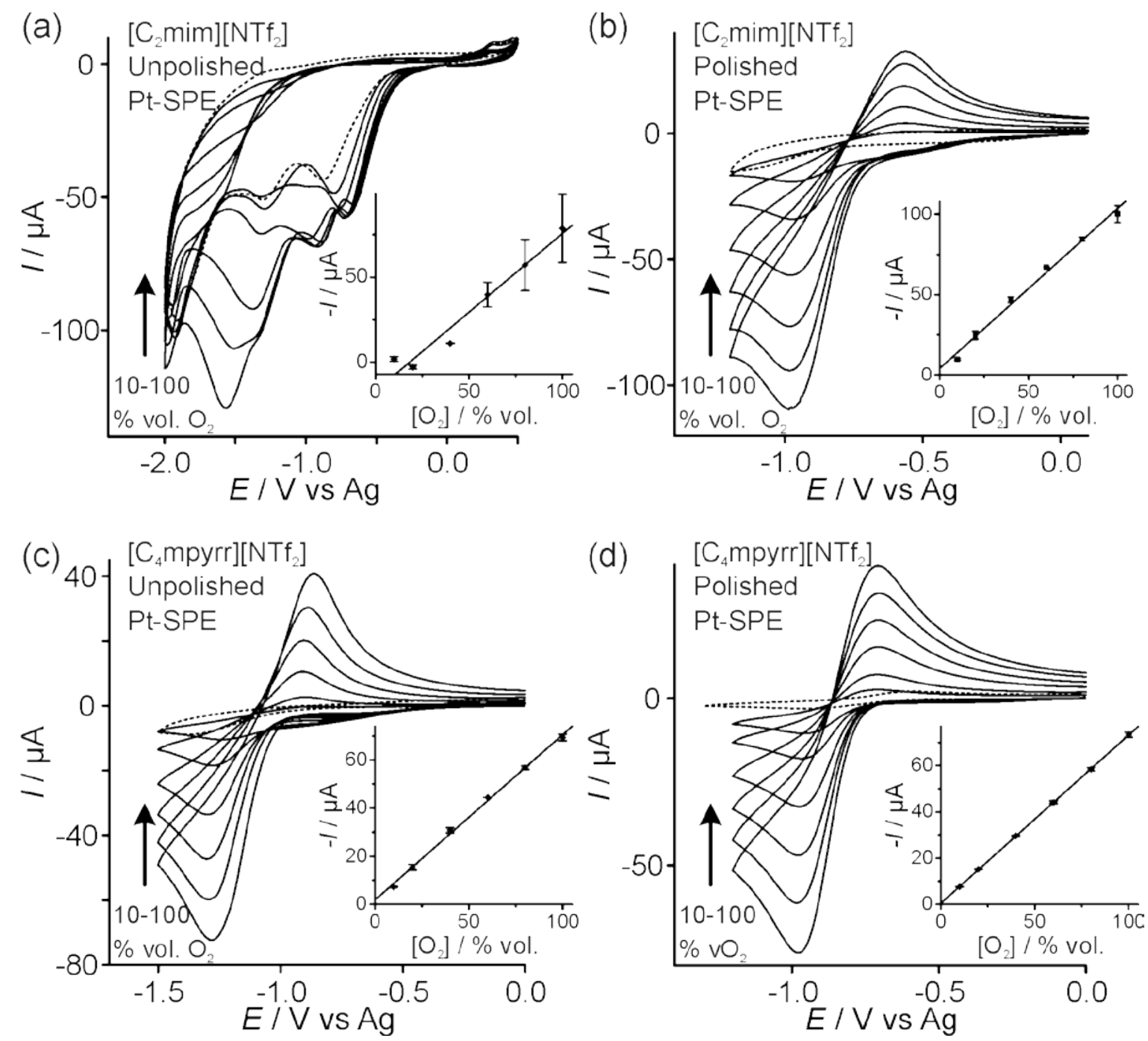

Figure 2. $\mathrm{CV}$ for $\mathrm{O}_{2}$ reduction in: $\left[\mathrm{C}_{2} \mathrm{mim}\right]\left[\mathrm{NTf}_{2}\right]$ on (a) an unpolished Pt-SPE and (b) a polished Pt-SPE, and in $\left[\mathrm{C}_{4}\right.$ mpyrr $]\left[\mathrm{NTf}_{2}\right]$ on (c) an unpolished Pt-SPE and (d) a polished Pt-SPE. Scan rate of $100 \mathrm{mVs}^{-1}$ at 10, 20, 40, 60, 80 and $100 \%$ vol. $\mathrm{O}_{2}$ after $120 \mathrm{CV}$ cycles in the presence of $100 \%$ vol. $\mathrm{O}_{2}$ was performed. The dotted lines are $\mathrm{CVs}$ in the absence of oxygen (after $120 \mathrm{CV}$ cycles in $100 \%$ vol. $\mathrm{O}_{2}$ ). The insets are the corresponding plots of $\mathrm{O}_{2}$ reduction peak current (background corrected) vs. \% vol. $\mathrm{O}_{2}$ in the flow, and the line of best-fit. Error bars are represented as one standard deviation of three separate calibrations on different days. Where they are not clearly visible, the error bars are smaller than the symbol size. 


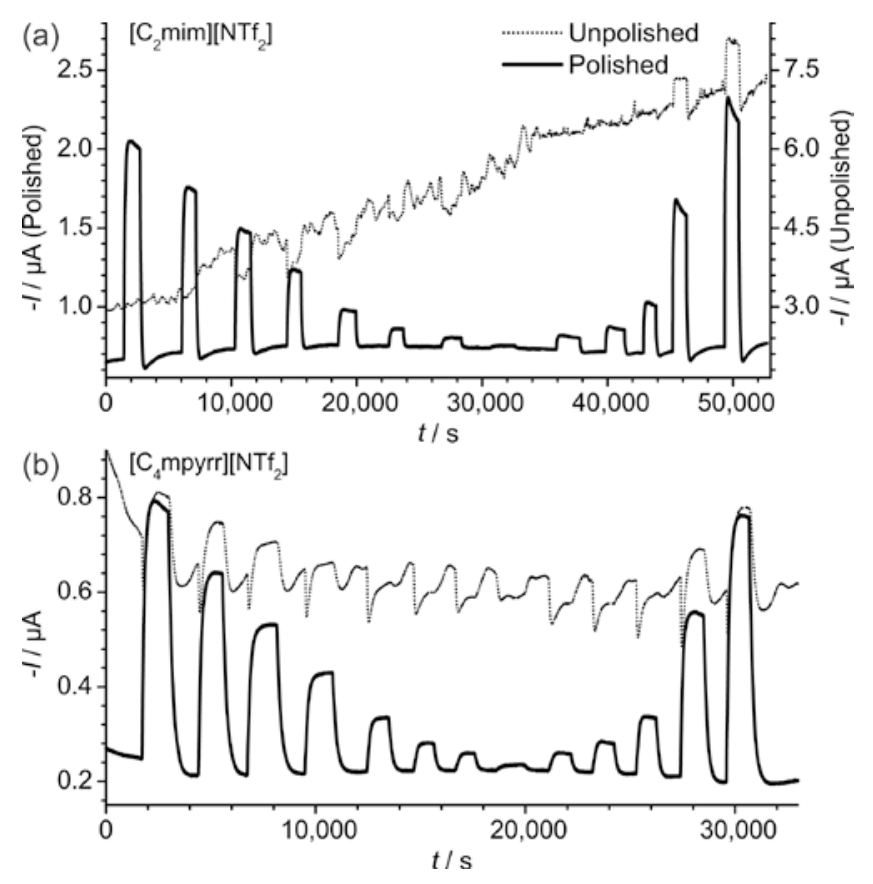

Figure 3. LTCA at different $\mathrm{O}_{2}$ gas concentrations in (a) $\left[\mathrm{C}_{2} \mathrm{mim}\right]\left[\mathrm{NTf}_{2}\right]$ and (b) $\left[\mathrm{C}_{4} \mathrm{mpyrr}\right]\left[\mathrm{NTf}_{2}\right]$ on unpolished (dotted line) and polished (solid line) Pt-SPEs. The gas flow was alternated between $\mathrm{N}_{2}$ and varying concentrations of $\mathrm{O}_{2}$ in the following order: $5,4,3,2,1,0.5,0.3,0.1,0.3,0.5,1,3,5 \%$ vol. 

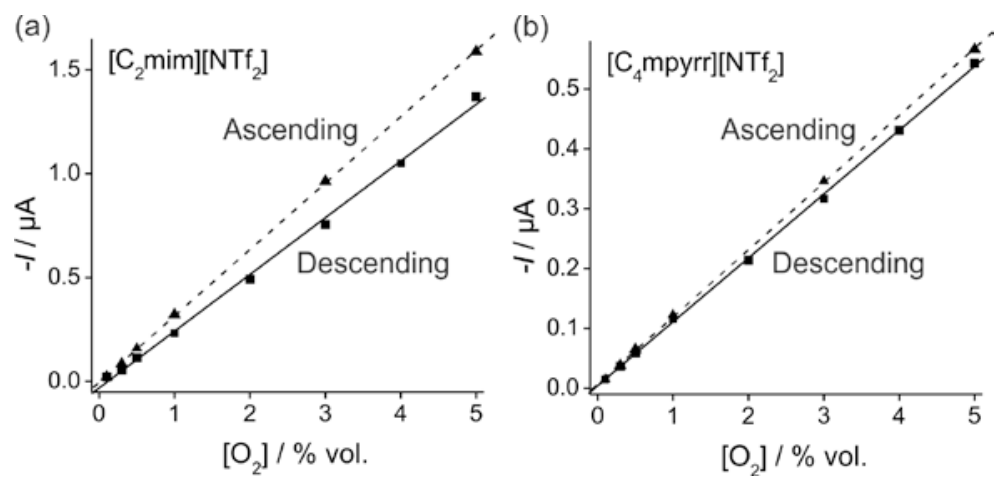

Figure 4. Plots of background corrected oxygen reduction currents vs. $\%$ vol. $\mathrm{O}_{2}$, and the lines of best-fit for (a) $\left[\mathrm{C}_{2} \mathrm{mim}\right]\left[\mathrm{NTf}_{2}\right]$ and (b) $\left[\mathrm{C}_{4} \mathrm{mpyrr}\right]\left[\mathrm{NTf}_{2}\right]$ on polished Pt-SPEs, extracted from LTCA measurements presented in Figure 3. The solid lines (-) represent the linear regression for the first eight 'descending' oxygen concentrations $(5,4,3,2,1,0.5,0.3,0.1 \%$ vol.), and the dashed lines (- -) for the last six 'ascending' oxygen concentrations (0.1, 0.3, 0.5, 1, 3, $5 \%$ vol., see Figure 3).

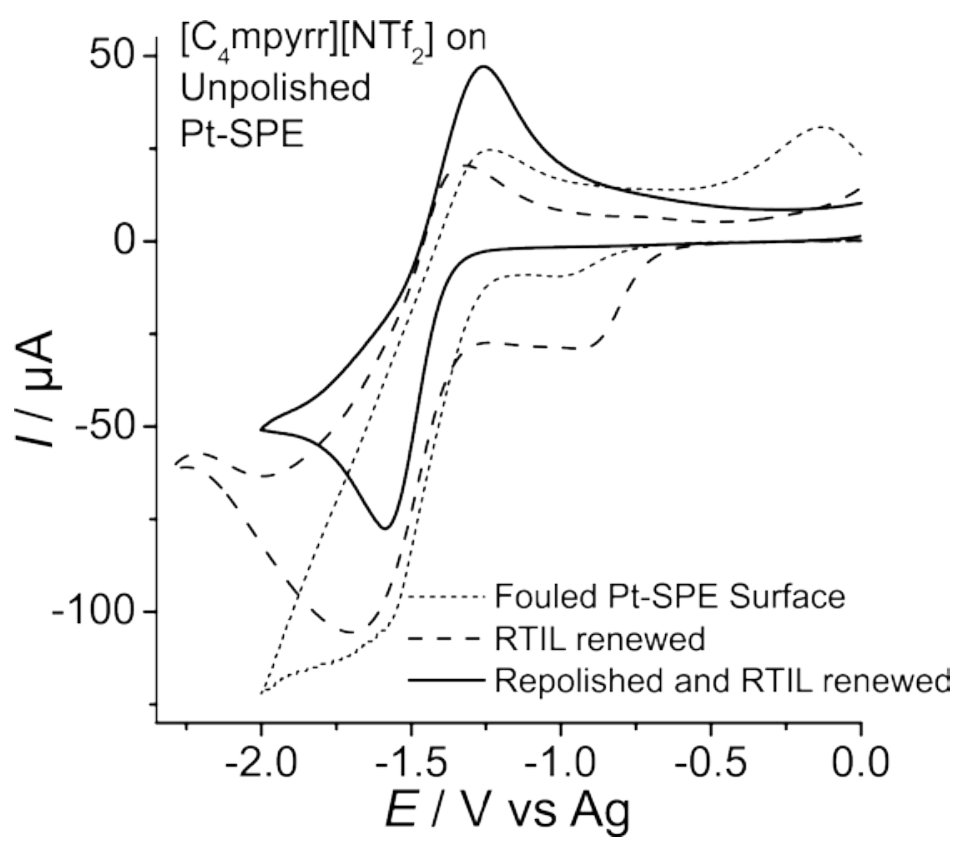

Figure 5. Recovery of fouled Pt-SPE surfaces after polishing. The dotted line ( $\cdots$ ) shows CV of $100 \% \mathrm{O}_{2}$ reduction on an unpolished Pt-SPE surface, degraded after long-term CV experiments (120 cycles) in $\left[\mathrm{C}_{4}\right.$ mpyrr $]\left[\mathrm{NTf}_{2}\right]$. The dashed line (- -) shows the CV after the RTIL (visibly browned) was rinsed off and a fresh $30 \mu \mathrm{L}$ aliquot applied. The solid line (-) shows the CV after the RTIL was rinsed off, and the surface polished before applying a fresh $30 \mu \mathrm{L}$ aliquot of the RTIL. Scans were conducted with a scan rate of $100 \mathrm{mVs}^{-1}$. 


\section{References:}

(1) Song, C.; Zhang, J.: Electrocatalytic Oxygen Reduction Reaction. In PEM Fuel Cell Electrocatalysts and Catalyst Layers; Zhang, J., Ed.; Springer London, 2008; pp 89-134.

(2) Toniolo, R.; Dossi, N.; Pizzariello, A.; Doherty, A. P.; Susmel, S.; Bontempelli, G. J. Electroanal. Chem. 2012, 670, 23-29.

(3) Göpel, W.; Reinhardt, G.; Rösch, M. Solid State Ionics 2000, 136-137, 519-531.

(4) Mills, A.; Tommons, C.; Bailey, R. T.; Crilly, P.; Tedford, M. C. Anal. Chim. Acta 2011, 702, 269273.

(5) Wang, R.; Okajima, T.; Kitamura, F.; Ohsaka, T. Electroanalysis 2004, 16, 66-72.

(6) Xiang, L.; Yu, P.; Zhang, M.; Hao, J.; Wang, Y.; Zhu, L.; Dai, L.; Mao, L. Anal. Chem. 2014, 86, 5017-5023.

(7) Buzzeo, M. C.; Evans, R. G.; Compton, R. G. ChemPhysChem 2004, 5, 1106-1120.

(8) Barrosse-Antle, L. E.; Bond, A. M.; Compton, R. G.; O 'Mahony, A. M.; Rogers, E. I.; Silvester, D. S. Chem. Asian J. 2010, 5, 202-230.

(9) Silvester, D. S.; Compton, R. G. Z. Phys. Chem. 2006, 220, 1247-1274.

(10) Buzzeo, M. C.; Hardacre, C.; Compton, R. G. Anal. Chem. 2004, 76, 4583-4588.

(11) Rehman, A.; Zeng, X. RSC Adv. 2015, 5, 58371-58392.

(12) Silvester, D. S. Analyst 2011, 136, 4871-4882.

(13) Rogers, E. I.; O'Mahony, A. M.; Aldous, L.; Compton, R. G. ECS Trans. 2010, 33, 473-502.

(14) Metters, J. P.; Kadara, R. O.; Banks, C. E. Analyst 2011, 136, 1067-1076.

(15) Murugappan, K.; Lee, J.; Silvester, D. S. Electrochem. Commun. 2011, 13, 1435-1438.

(16) Lee, J.; Murugappan, K.; Arrigan, D. W. M.; Silvester, D. S. Electrochim. Acta 2013, 101, 158168.

(17) Gębicki, J.; Kloskowski, A.; Chrzanowski, W. Electrochim. Acta 2011, 56, 9910-9915.

(18) Xiong, S.-Q.; Wei, Y.; Guo, Z.; Chen, X.; Wang, J.; Liu, J.-H.; Huang, X.-J. J. Phys. Chem. C 2011, 115, 17471-17478.

(19) Murugappan, K.; Arrigan, D. W. M.; Silvester, D. S. J. Phys. Chem. C 2015, 119, 23572-23579.

(20) Murugappan, K.; Silvester, D. S. Sensors 2015, 15, 26866-26876.

(21) Lee, J.: PhD thesis: Electrochemical Sensing of Oxygen Gas in Ionic Liquids on Screen Printed Electrodes. Curtin University, 2014.

(22) Bonhôte, P.; Dias, A.-P.; Papageorgiou, N.; Kalyanasundaram, K.; Grätzel, M. Inorg. Chem. 1996, 35, 1168-1178.

(23) MacFarlane, D. R.; Meakin, P.; Sun, J.; Amini, N.; Forsyth, M. J. Phys. Chem. B 1999, 103, 4164-4170.

(24) Fanjul-Bolado, P.; Hernández-Santos, D.; Lamas-Ardisana, P. J.; Martín-Pernía, A.; Costa-García, A. Electrochim. Acta 2008, 53, 3635-3642.

(25) Kadara, R. O.; Jenkinson, N.; Banks, C. E. Sens. Act. B 2009, 138, 556-562.

(26) Zhao, C.; Bond, A. M.; Lu, X. Anal. Chem. 2012, 84, 2784-2791.

(27) Zhang, J.; Bond, A. M.; MacFarlane, D. R.; Forsyth, S. A.; Pringle, J. M.; Mariotti, A. W. A.; Glowinski, A. F.; Wedd, A. G. Inorg. Chem. 2005, 44, 5123-5132.

(28) Switzer, E. E.; Zeller, R.; Chen, Q.; Sieradzki, K.; Buttry, D. A.; Friesen, C. J. Phys. Chem. C 2013, 117, 8683-8690.

(29) James, S. D. J. Electrochem. Soc. 1967, 114, 1113-1119.

(30) Huang, X. J.; Aldous, L.; O'Mahony, A. M.; del Campo, F. J.; Compton, R. G. Anal. Chem, 2010, 82, 5238-5245.

(31) AlNashef, I. M.; Hashim, M. A.; Mjalli, F. S.; Al-haj Ali, M. Q.; Hayyan, M. Tetrahedron Lett. 2010, 51, 1976-1978.

(32) Islam, M. M.; Imase, T.; Okajima, T.; M., T.; Niikura, Y.; Kawashima, N.; Nakamura, Y.; Ohsaka, T. J. Phys. Chem. A 2009, 113, 912-916.

(33) Frith, J. T.; Russell, A. E.; Garcia-Araez, N.; Owen, J. R. Electrochem. Commun. 2014, 46, 33-35. 
(34) Buzzeo, M. C.; Klymenko, O. V.; Wadhawan, J. D.; Hardacre, C.; Seddon, K. R.; Compton, R. G. J. Phys. Chem. A 2003, 107, 8872-8878. 
Table of Contents Figure

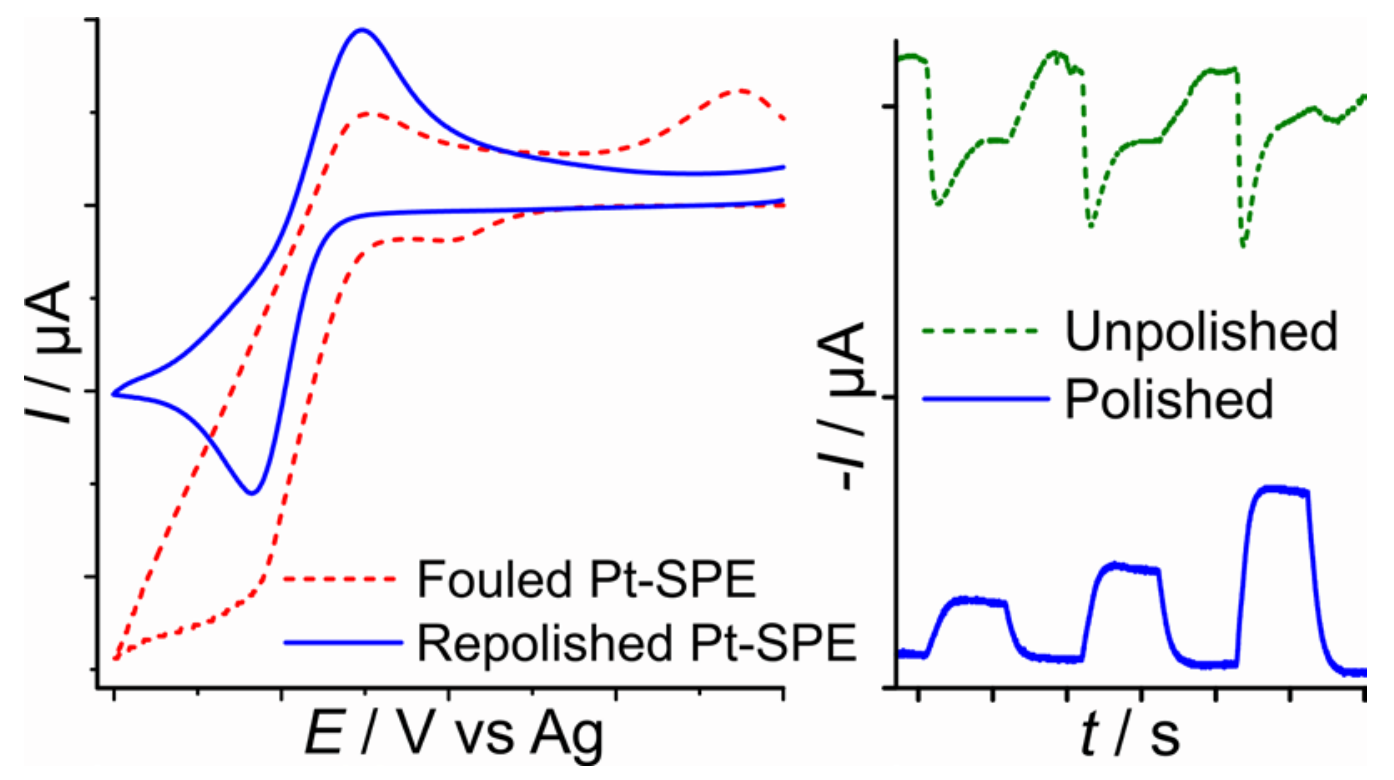

